\title{
Property norms for typical and atypical items from 17 categories: A description and discussion
}

\author{
MARK H. ASHCRAFT \\ Cleveland State University, Cleveland, Ohio 44115
}

\begin{abstract}
A description is presented of normative data for property responses to 121 words- 17 category labels, three typical and three atypical members of each category, and the words "plant" and "animal." The production frequency of properties is considered a measure of property dominance or semantic relatedness, and has been validated for the present data as a significant predictor of reaction time to property statements. Additional data include measures that support definitions of typicality in terms of property overlap between member and category, criteriality or dominance of the superordinate term, and the average number of properties generated to the category member. In reverse order, these three variables provide the best prediction of rated typicality. Average number of properties and superordinate dominance were the more important variables in this prediction, were virtually independent statistically, and were approximately equal in their contribution. Implications for semantic memory models are discussed.
\end{abstract}

An increasing number of experiments have been concerned with semantic memory for properties or attributes; that is, memory for such characteristics of birds as wings, feet, feathers, and fly. Collins and Quillian $(1969,1970,1972)$ stimulated a great deal of research in this area with their proposal of hierarchical memory structure and inferential processing for concepts and properties. Subsequently, Conrad (1972), Glass, Holyoak, and O'Dell (1974), Holyoak, Glass, and Mah (1976), Nelson and Kosslyn (1976), and Rips (1975), among others, have explored various aspects of semantic memory for properties. The growing importance of this area of research is demonstrated not only by the number of reports in the literature, but also by the inclusion of these results and issues in current models of semantic memory (e.g., Kintsch, 1974, Chapter 10; Norman \& Rumelhart, 1975, Chapter 2; Smith, Rips, \& Shoben, 1974).

The first major variable of interest in the present research was property dominance, operationally defined as the production frequency of properties generated to various categories and category members. It is generally conceded that production frequency measures provide good empirical estimates of semantic relatedness (e.g., Loftus \& Suppes, 1972), and that semantic relatedness, in its various theoretical forms, is the most basic variable identified so far in the study of semantic memory. In the present research, property dominance or frequency serves as the basic index of semantic

This research was partially supported by a Rescarch Initiation Award from the Cleveland State University. I would like to thank Lisa Morrow for help in preparing the data for publication, and Tom Incorvia for assisting in the computer tabulations. Reprint requests should be addressed to the author, Department of Psychology, Cleveland State University, Cleveland, Ohio 44115. relatedness between concepts and their properties. The original purpose of this project was simply to obtain a comprehensive catalogue of property responses and dominance values to be used as a reference source of stimuli for property verification studies, as less ambitious norms have been used previously (e.g., Ashcraft, 1976; Glass et al., 1974).

The second major theoretical issue addressed by the normative data is that of "typicality" (Smith et al, 1974) or "goodness of exemplar" (Rosch, 1975). Items in the norms were selected from both the typical and atypical levels of category membership. The resulting data permit an evaluation of typicality in terms of several recently presented theoretical definitions. In particular, the results presented here examine the concept of an item's typicality in terms of: (1) the number of common properties (Collins \& Loftus, 1975 ) or the amount of feature overlap (Smith et al., 1974) between a category member and its superordinate; (2) the degree of dominance or criteriality (Collins \& Loftus, 1975) between a category member and its superordinate; (3) the amount of accessible information stored about a category member (Ashcraft, in press), and (4) the uniformity of a concept's semantic representation across individuals.

The present paper summarizes the methods and results of the normative property dominance study and presents evidence from the norms relating to semantic relatedness and typicality. Only a small portion of the actual property responses is presented here; the complete set of responses in the norms is available upon request (Ashcraft, Note 1).

\section{METHOD}

Seventeen categories were selected from the Battig and Montague $(1969)$ norms. A preliminary study $(n=30)$ replicated 
Rosch's (1975) procedures on this larger sample of categories in order to identify items that are considered typical and atypical members of the 17 categories. On this basis, three typical and three atypical items from each category were selected. Each of the 101 subjects gave responses to a random half of the total word sample which included 102 category members, the 17 category names, and the words "plant" and "animal." Subjects were told that the task involved writing down the "properties and characteristics that people generally attribute to various objects or things.... In general, the properties you write down can be introduced by the words 'is,' 'has,' 'can,' or 'is a' [examples provided], although other kinds of properties are equally permissible and may also be written down." Subjects were given $40 \mathrm{sec} /$ word in which to list all the properties they could think of. All legible property responses were coded for computer tabulation.

\section{RESULTS AND DISCUSSION}

The summary table of results is presented in the Appendix, due to the length of the table. The data are organized as follows: Reading down the table, the 17 categories are listed alphabetically; within each category, the three typical members are listed first, followed by the three atypical members. Reading across the table, each category member is followed by (1) its rated typicality in the category (scale from 1 to 10 ); (2) the percentage of the member's properties that were also listed for its superordinate, that is the percentage property overlap; (3) the production frequency of the superordinate term as a property response to the member, expressed as a percentage; (4) the mean number of properties generated to the word per subject; (5) the number of "high-dominant" properties generated, that is, the number of properties with a production frequency of at least $50 \%$; and (6) the five most frequent properties for that word, each accompanied by its percentage production frequency.

Approximately one-third to one-half of the property responses to all words were generated only once. For the most part, these single-frequency properties were quite idiosyncratic, and they have been excluded from all calculations reported here. The number of properties produced at least twice ranged in the sample from 9 (to "jonquil") to 53 (to "musical instrument"). The production frequency tabulation for each stimulus word demonstrated rates of generation from a high of $94 \%$ ("sharp" as a property of "knife") to only one occurrence. The nature of the property responses was quite varied, including "part of," location, and action properties, properties clearly unique to the item or general to the category, superordinate properties, and various word associates of mixed character (e.g., "rain" and "mink" as properties of "coat," "Jack Benny" as a property of "violin").

Internal reliability of the production frequency measure was assessed by dividing the subjects randomly into two groups and correlating the production frequencies. All of the correlations were positive and significant beyond the .005 level. The validity of production frequency as an index of semantic relatedness, and as a predictor of reaction time (RT) performance, has been tested previously for smaller sets of norms (e.g., Ashcraft, 1976; Glass et al., 1974). For the present data, properties were selected for two typical and two atypical members of each category from both the high and low frequency ranges, and the resultant property statements were presented in a verification task. Stepwise multiple regressions on RT revealed a strong effect of production frequency. In all cases, the production frequency measure was the first to enter the regression equation and was the single most important variable evaluated (e.g., $\mathrm{F}$ to enter $=31.74, \mathrm{p}<.001, \mathrm{r}=-.46 ; \mathrm{a}$ complete report of this experiment is given by Ashcraft, in press).

As stated, category members were selected on the basis of rated typicality (Appendix, Column 1). There was a significant difference between the typical and atypical words on rated typicality $[\mathrm{t}(100)=10.62$, $\mathrm{p}<.001]$. Columns 2.5 in the Appendix present data that permit an explicit examination of several different theoretical accounts of typicality.

Smith et al. (1974; see also Rosch, 1975) have argued that items considered typical of their categories should have higher feature overlap with the superordinate than those considered atypical in their categories. According to Smith et al., this differential feature overlap between category members and their superordinates accounts for verification time differences in category statement experiments. Consistent with the Smith et al. model, there was a significantly higher overlap of properties (Appendix, Column 2) between typical members and superordinates than between atypical members and superordinates $[\mathrm{t}(100)=3.58$, $\mathrm{p}<.001$; mean overlap $=40.1 \%(\mathrm{SD}=12.4)$ and $31.1 \%(\mathrm{SD}=12.9)$, respectively]. Note that this result is also in agreement with Collins and Loftus' (1975, Assumption 10) statement about the nature of memory search and typicality.

In addition to the overlap or common properties notion, Collins and Loftus (1975, Assumption 9) maintain that a retrieved link to a superordinate is important in semantic searches, and in particular that the criteriality or dominance of this link is important. Column 3 of the Appendix presents the production frequency of the superordinate term for each category member. Average production frequency of the superordinate was significantly higher for typical vs. atypical members $[\mathrm{t}(100)=4.29, \mathrm{p}<.001 ;$ means $=40.3 \%$ $(\mathrm{SD}=23.2)$ and $22.4 \% \quad(\mathrm{SD}=18.6)$, respectively $]$.

Two additional indices of typicality not specifically included in current models are advanced here as a function of the analysis of property responses of Ashcraft (Note 1); although new, their theoretical relationship to typicality seems fairly obvious. First, it is commonly assumed that objects that are encountered more often, and hence are more familiar or salient, 
become the typical members of their categories. Accordingly, it seems likely that typical members would be represented more completely and elaborately in semantic memory, permitting more properties to be generated in a normative task. Column 4 in the Appendix presents the average number of generated properties to each stimulus word. In support of the above prediction, typical category members were significantly higher than atypical members in the number of properties generated $[\mathrm{t}(100)=4.75$, $\mathrm{p}<.001 ;$ means $=5.6(\mathrm{SD}=.69)$ and $4.7(\mathrm{SD}=1.13)$, respectively]. A second corollary of typicality is that typical items are likely to be more uniformly represented in memory across individuals (cf. Rosch \& Mervis, 1975), yielding higher incidence of agreement across subjects on the properties of typical category members. Support for this idea is indicated in the data in Column 5 of the Appendix, which contains the total number of properties per stimulus word generated by at least $50 \%$ of the subjects. The number of these "high-dominant" properties is greater for typical vs. atypical category members $[\mathrm{t}(100)=3.77$, $\mathrm{p}<.001 ;$ means $=1.64(\mathrm{SD}=1.14)$ and $.90(\mathrm{SD}=.81)$, respectively] .

Although the four analyzed factors are clearly related to typicality, no compelling basis emerges from the above data to indicate which factor might be the more basic determinant of typicality. To pursue the nature of typicality further, then, a stepwise multiple-regression analysis, employing the rated typicality value as the dependent measure, was conducted; Table 1 presents the correlation matrix for six variables, the Columns $1-5$ measures and the highest frequency in Column 6 . The first variable selected in the regression analysis was the mean number of properties variable $[F(1,100)=25.56, \quad \mathrm{p}<.001, \quad \mathrm{MSe}=3.12]$. This variable alone accounted for $20 \%$ of the variance in rated typicality $(r=.45)$. The dominance of the superordinate entered the equation next [partial $\mathrm{r}=.43, \mathrm{~F}$ to enter $(1,99)=22.43, \mathrm{p}<.001]$, followed by the percent overlap variable [partial $\mathrm{r}=.20, \mathrm{~F}$ to enter $(1,98)=3.97$, $\mathrm{p}<.05]$. The three-term equation was significant $[F(3,98)=19.68, p<.001, \mathrm{MSe}=2.49]$ and accounted for $35 \%$ of the variance (multiple $r=.61$ ).

This is a particularly interesting pattern of results. Not only was the mean number of properties the most important predictor of rated typicality here, but in the Ashcraft (in press) study, the same variable was found to be a better predictor of RT than either rated typicality or a dichotomous typicality measure. In that report, this effect was interpreted as indicating
Table 1

Correlation Matrix for Six Typicality Variables

\begin{tabular}{ccrrrrr}
\hline $\begin{array}{c}\text { Varia- } \\
\text { bles }\end{array}$ & \multicolumn{1}{c}{1} & \multicolumn{1}{c}{2} & 3 & 4 & 5 & 6 \\
\hline 1 & 1.000 & & & & & \\
2 & .265 & 1.000 & & & & \\
3 & .429 & .246 & 1.000 & & & \\
4 & .451 & .039 & .106 & 1.000 & & \\
5 & .338 & .204 & .290 & .423 & 1.000 & \\
6 & .151 & -.020 & .219 & .467 & .572 & 1.000 \\
\hline
\end{tabular}

Note-For 102 cases, critical values of $r=.197(\alpha=.05)$ and $.257(\alpha=.01)$

that more information is accessible for typical vs. atypical category members, and that there are more interconnections among properties and members at the typical level of category membership. Both of these conditions, according to the Collins and Loftus (1975) model, should lead to faster verification of property statements. In combination with the present results, it may in fact be the case that a greater amount of accessible information both allows for faster verification and also serves as the semantic determinant of higher typicality per se. The low intercorrelation between the mean number of properties and superordinate dominance variables and the unchanged partial correlation of superordinate dominance to rated typicality suggest that finding a link to the superordinate may be a virtually independent alternative process in judging typicality.

The general issue behind both typicality and property dominance is that of the nature of semantic representation, and the search and decision processes that operate on that representation. A variety of theoretical positions are currently available to account for typicality, including feature overlap with the superordinate and criteriality of the superordinate. The present data suggest that these definitions must be broadened to account for the positive relationship between amount of stored information and rated typicality. In general, the present results suggest that typicality ratings, and by analogy other decisions that involve typicality as a component, may be based on either of two apparently independent processes. The theoretical flexibility necessary to be compatible with results such as these is embodied, for example, in the Collins and Loftus (1975) model, at the expense, however, of simplicity in prediction. The value of the present data, at this stage, is to illustrate the need for this flexibility, and to provide an objective basis for further investigation of semantic memory for properties.

Appendix

Summary of Property Norms From Ashcraft (Note 1)

\begin{tabular}{|c|c|c|c|c|c|c|}
\hline Category* & 1 & 2 & 3 & 4 & 5 & 6 \\
\hline Beverage & & & & 5.0 & 2 & drink-61, liquid- 54, cool- 38 , hot -21 , refreshes- 21 \\
\hline Coffee & 8.89 & 29 & 29 & 6.1 & 0 & black-35, bean-33, drink-29, bitter-27, hot-27 \\
\hline
\end{tabular}


Appendix Continued

\begin{tabular}{|c|c|c|c|c|c|c|}
\hline Category* & 1 & 2 & 3 & 4 & 5 & 6 \\
\hline $\begin{array}{l}\text { Tea } \\
\text { Milkshake } \\
\text { Soup } \\
\text { Tonic }\end{array}$ & $\begin{array}{l}8.81 \\
8.00 \\
3.59 \\
5.44\end{array}$ & $\begin{array}{l}23 \\
20 \\
26 \\
39\end{array}$ & $\begin{array}{r}47 \\
21 \\
6 \\
20\end{array}$ & $\begin{array}{l}5.3 \\
6.6 \\
4.6 \\
3.6\end{array}$ & $\begin{array}{l}0 \\
2 \\
1 \\
0\end{array}$ & $\begin{array}{l}\text { drink }-47 \text {, hot }-43 \text {, leave }-41 \text {, brown- } 39 \text {, bitter- } 23 \\
\text { cold }-57 \text {, thick- } 51 \text {, ice cream- } 43 \text {, chocolate- } 38 \text {, creamy- } 32 \\
\text { hot- } 65 \text {, liquid- }-39 \text {, vegetable- } 31 \text {, noodle-20, warm-20 } \\
\text { liquid } 48 \text {, medicine- } 29 \text {, drink- } 20 \text {, hair- } 18 \text {, clear- } 16\end{array}$ \\
\hline $\begin{array}{l}\text { Bird } \\
\text { Bluejay } \\
\text { Robin } \\
\text { Sparrow } \\
\text { Chicken } \\
\text { Duck } \\
\text { Owl }\end{array}$ & $\begin{array}{l}9.63 \\
9.70 \\
9.36 \\
6.56 \\
7.41 \\
8.22\end{array}$ & $\begin{array}{l}72 \\
63 \\
63 \\
43 \\
50 \\
35\end{array}$ & $\begin{array}{l}62 \\
70 \\
66 \\
24 \\
17 \\
49\end{array}$ & $\begin{array}{l}6.3 \\
6.0 \\
6.1 \\
5.7 \\
5.6 \\
5.6 \\
6.1\end{array}$ & $\begin{array}{l}4 \\
5 \\
4 \\
3 \\
2 \\
1 \\
1\end{array}$ & 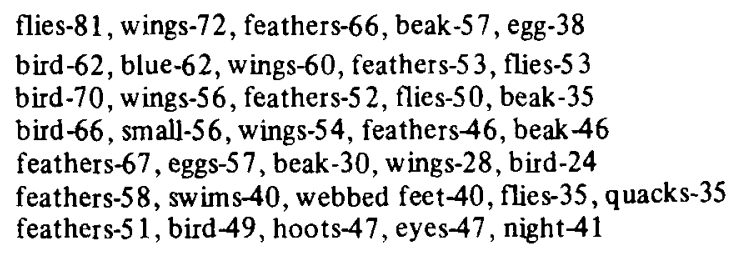 \\
\hline $\begin{array}{l}\text { Building } \\
\text { Castle } \\
\text { Hotel } \\
\text { House } \\
\text { Cabin } \\
\text { Hut } \\
\text { Shack }\end{array}$ & $\begin{array}{l}9.56 \\
9.45 \\
9.36 \\
7.36 \\
5.36 \\
6.00\end{array}$ & $\begin{array}{l}23 \\
15 \\
44 \\
12 \\
15 \\
33\end{array}$ & $\begin{array}{r}8 \\
24 \\
0 \\
0 \\
0 \\
11\end{array}$ & $\begin{array}{l}6.4 \\
5.8 \\
5.4 \\
6.8 \\
5.5 \\
5.2 \\
4.9\end{array}$ & $\begin{array}{l}0 \\
0 \\
1 \\
0 \\
2 \\
0 \\
1\end{array}$ & 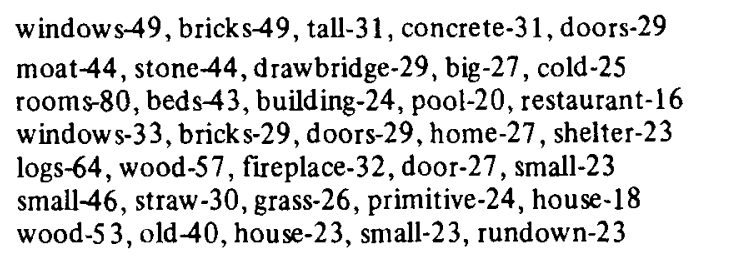 \\
\hline $\begin{array}{l}\text { Cloth } \\
\text { Cotton } \\
\text { Flannel } \\
\text { Linen } \\
\text { Burlap } \\
\text { Canvas } \\
\text { Nylon }\end{array}$ & $\begin{array}{l}9.00 \\
9.22 \\
9.56 \\
6.22 \\
5.33 \\
5.33\end{array}$ & $\begin{array}{l}37 \\
30 \\
37 \\
42 \\
30 \\
48\end{array}$ & $\begin{array}{l}16 \\
31 \\
41 \\
16 \\
28 \\
15\end{array}$ & $\begin{array}{l}4.9 \\
4.8 \\
4.6 \\
4.3 \\
4.6 \\
3.9 \\
4.4\end{array}$ & $\begin{array}{l}3 \\
2 \\
2 \\
0 \\
1 \\
0 \\
1\end{array}$ & 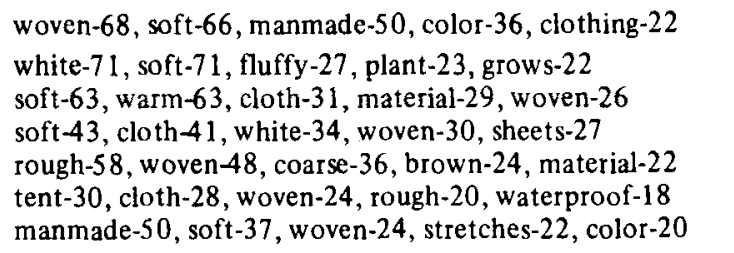 \\
\hline $\begin{array}{l}\text { Clothing } \\
\text { Coat } \\
\text { Dress } \\
\text { Shirt } \\
\text { Belt } \\
\text { Glove } \\
\text { Scarf }\end{array}$ & $\begin{array}{l}9.55 \\
9.27 \\
9.91 \\
5.27 \\
6.27 \\
5.64\end{array}$ & $\begin{array}{l}44 \\
33 \\
32 \\
10 \\
29 \\
37\end{array}$ & $\begin{array}{r}14 \\
19 \\
15 \\
0 \\
6 \\
7\end{array}$ & $\begin{array}{l}4.8 \\
5.6 \\
5.4 \\
5.8 \\
5.2 \\
4.8 \\
5.4\end{array}$ & $\begin{array}{l}1 \\
1 \\
0 \\
3 \\
2 \\
2 \\
1\end{array}$ & 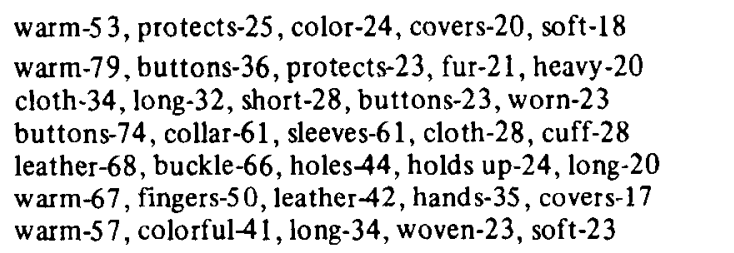 \\
\hline $\begin{array}{l}\text { Fish } \\
\text { Salmon } \\
\text { Trout } \\
\text { Tuna } \\
\text { Minnow } \\
\text { Shrimp } \\
\text { Sunfish }\end{array}$ & $\begin{array}{l}8.93 \\
9.55 \\
8.59 \\
7.59 \\
5.76 \\
6.79\end{array}$ & $\begin{array}{l}52 \\
57 \\
50 \\
50 \\
32 \\
54\end{array}$ & $\begin{array}{l}79 \\
75 \\
78 \\
62 \\
23 \\
40\end{array}$ & $\begin{array}{l}5.8 \\
5.0 \\
5.9 \\
5.2 \\
4.8 \\
4.7 \\
4.1\end{array}$ & $\begin{array}{l}2 \\
1 \\
1 \\
1 \\
2 \\
0 \\
0\end{array}$ & 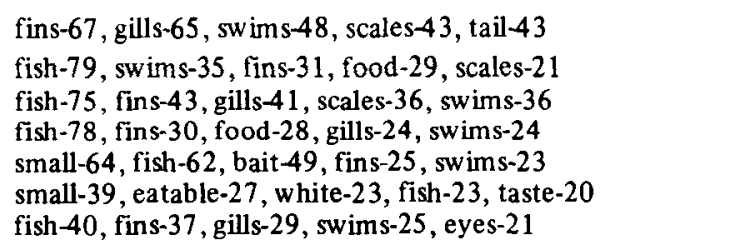 \\
\hline $\begin{array}{l}\text { Flower } \\
\text { Daisy } \\
\text { Lily } \\
\text { Rose } \\
\text { Jonquil } \\
\text { Lilac } \\
\text { Peony }\end{array}$ & $\begin{array}{r}9.40 \\
9.20 \\
10.00 \\
6.20 \\
8.10 \\
7.50\end{array}$ & $\begin{array}{l}61 \\
59 \\
56 \\
67 \\
51 \\
39\end{array}$ & $\begin{array}{l}77 \\
65 \\
58 \\
11 \\
61 \\
35\end{array}$ & $\begin{array}{l}6.0 \\
5.6 \\
5.1 \\
6.9 \\
1.6 \\
4.9 \\
3.1\end{array}$ & $\begin{array}{l}0 \\
3 \\
2 \\
3 \\
1 \\
1 \\
0\end{array}$ & 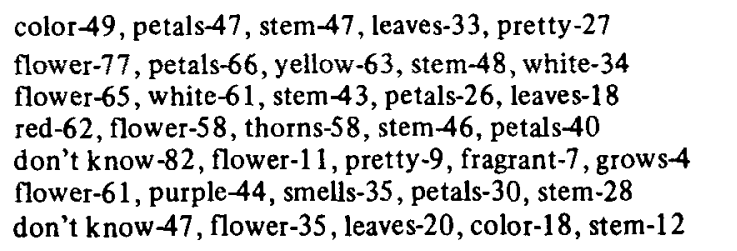 \\
\hline $\begin{array}{l}\text { Fruit } \\
\text { Apple } \\
\text { Grape } \\
\text { Pear } \\
\text { Fig } \\
\text { Olive } \\
\text { Raisin }\end{array}$ & $\begin{array}{l}9.90 \\
9.14 \\
9.76 \\
6.62 \\
3.76 \\
6.83\end{array}$ & $\begin{array}{l}55 \\
43 \\
43 \\
29 \\
36 \\
31\end{array}$ & $\begin{array}{l}57 \\
50 \\
70 \\
49 \\
15 \\
39\end{array}$ & $\begin{array}{l}5.7 \\
7.3 \\
6.1 \\
5.5 \\
3.8 \\
5.3 \\
4.9\end{array}$ & $\begin{array}{l}0 \\
2 \\
2 \\
2 \\
0 \\
1 \\
0\end{array}$ & 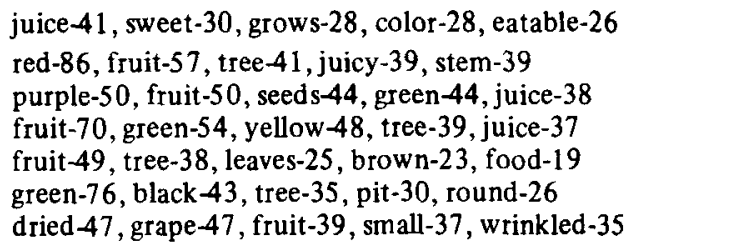 \\
\hline Furniture & & & & 5.6 & 1 & wood -59 , metal-18, legs-18, comfortable-18, manmade-14 \\
\hline $\begin{array}{l}\text { Chair } \\
\text { Sofa } \\
\text { Table } \\
\text { Bench } \\
\text { Rug } \\
\text { Shelf }\end{array}$ & $\begin{array}{l}9.83 \\
9.80 \\
9.57 \\
5.80 \\
2.67 \\
3.40\end{array}$ & $\begin{array}{l}42 \\
49 \\
45 \\
27 \\
20 \\
20\end{array}$ & $\begin{array}{r}7 \\
18 \\
7 \\
4 \\
0 \\
0\end{array}$ & $\begin{array}{l}5.4 \\
5.7 \\
5.8 \\
4.7 \\
4.8 \\
4.2\end{array}$ & $\begin{array}{l}2 \\
1 \\
2 \\
1 \\
0 \\
1\end{array}$ & 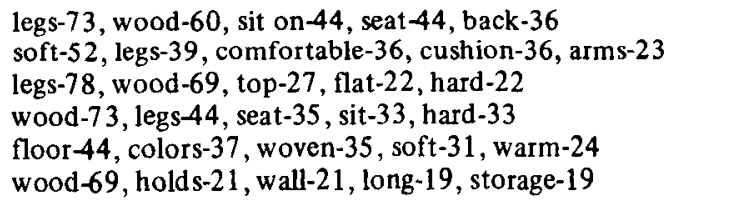 \\
\hline
\end{tabular}


Appendix Continued

\begin{tabular}{|c|c|c|c|c|c|c|}
\hline Category* & 1 & 2 & 3 & 4 & 5 & 6 \\
\hline Insect & & & & 5.0 & 1 & small- 50 , wings- 32 , crawls- 26 , flies -24 , legs- 24 \\
\hline Ant & 9.78 & 32 & 45 & 5.2 & 2 & small -58 , black -53 , insect -45 , legs -41 , red -29 \\
\hline Bee & 10.00 & 21 & 29 & 5.8 & 2 & sting -92 , honey -61 , flies -49 , wings -43 , buzzes -41 \\
\hline Moth & 8.56 & 29 & 44 & 4.7 & 2 & flies- 56 , wings -56 , insect -44 , attracted by light -20 , eats cloth -18 \\
\hline Chigger & 5.78 & 21 & 24 & 2.8 & 0 & don't know 41 , insect- 24 , bites- 22 , small- 22 , legs- 15 \\
\hline Spider & 6.00 & 24 & 31 & 5.2 & 1 & legs- 84 , web -49 , crawls- 37 , insect -31 , small- 29 \\
\hline Tick & 6.11 & 26 & 34 & 4.0 & 0 & insect-34, small-24, pest-18, bug-18, clock-16 \\
\hline Mammal & & & & 4.3 & 0 & warm blooded -32 , animal- 28 , hair- 26 , man- 17 , milk-15 \\
\hline Bear & 9.67 & 31 & 29 & 6.7 & 1 & fur -67, brown- 39, claws- 39, big- 37, animal -29 \\
\hline Horse & 9.33 & 25 & 49 & 6.7 & 2 & four legs -62 , tail- 55 , animal- 49 , hooves -25 , ride -25 \\
\hline Lion & 9.33 & 23 & 41 & 6.7 & 0 & fur -41, animal- -41, mane- 37, king- 30, roars- 27 \\
\hline Goat & 7.67 & 24 & 41 & 6.2 & 1 & horns- 55 , milk -49 , animal -41 , fur- 33 , hooves -26 \\
\hline Lamb & 6.78 & 26 & 31 & 5.4 & 1 & wool- 76 , white -41 , legs- 35 , animal- 31 , soft -28 \\
\hline Rabbit & 6.67 & 28 & 31 & 7.0 & 1 & fur-67, tail-47, soft-39, white-39, long ears-39 \\
\hline Musical Instrument & & & & 5.2 & 0 & sound-35, strings- 24 , wood- 24 , played- 22 , music- 18 \\
\hline Flute & 9.50 & 34 & 48 & 5.5 & 1 & music-59, instrument 48, holes -41 , long- 32, metal- 21 \\
\hline Piano & 10.00 & 47 & 38 & 6.0 & 2 & keys- 73 , music -65 , instrument -38 , strings- 36 , wood -31 \\
\hline Violin & 10.00 & 21 & 47 & 5.7 & 2 & strings -92 , music -51 , instrument -47 , wood -45 , bow 45 \\
\hline Banjo & 7.50 & 25 & 43 & 4.8 & 2 & strings -92 , music- 59 , instrument -43 , round -22 , played -18 \\
\hline Drum & 7.40 & 32 & 34 & 4.6 & 0 & round- 38, beat -36, sticks- 36, loud- 34, instrument- 34 \\
\hline Tuba & 7.20 & 52 & 56 & 6.0 & 2 & instrument -56 , brass -52 , loud 40 , music- 34 , big- 34 \\
\hline Tools & & & & 3.9 & 0 & useful-43, metal-34, work-12, hammer-12, wood- 12 \\
\hline Chisel & 8.30 & 38 & 46 & 4.1 & 0 & tool-46, metal-39, hard-30, steel- 23 , chip- 17 \\
\hline Hammer & 9.80 & 38 & 44 & 5.0 & 2 & handle -52 , wood -50 , tool -44 , metal- 43 , pound -33 \\
\hline Nail & 9.70 & 31 & 6 & 5.6 & 3 & metal-51, point-51, head-51, hard-37, sharp-33 \\
\hline Axe & 5.00 & 29 & 26 & 5.2 & 2 & sharp-76, handle- 57 , chop -47 , wood- 39 , cut-39 \\
\hline Crowbar & 6.00 & 21 & 46 & 5.2 & 0 & tool -46, heavy -38 , hard- 38 , metal- 31 , black -27 \\
\hline Ladder & 6.70 & 32 & 0 & 4.7 & 1 & wood -73 , steps -44 , rungs- 37 , climb-37, metal-31 \\
\hline Tree & & & & 6.6 & 2 & leaves- 89 , branches -58 , trunk -47 , roots- 40 , bark- 31 \\
\hline Maple & 9.89 & 32 & 74 & 5.2 & 3 & tree- 74 , syrup-61, leaves- 57 , sweet-22, wood-16 \\
\hline Oak & 9.78 & 38 & 67 & 5.3 & 2 & tree -67 , leaves -52 , wood -37 , hard -31 , branches- 25 \\
\hline Pine & 9.11 & 48 & 78 & 5.0 & 2 & tree- 78, needles- 52 , cones -41, green- 35, smells- 26 \\
\hline Bamboo & 4.11 & 19 & 4 & 4.1 & 0 & wood -39 , hollow- 26 , long- 22 , pole- 20 , brown- 17 \\
\hline Cyprus & 7.22 & 48 & 44 & 3.5 & 0 & tree-44, leaves-22, don't know-22, Florida-18, gardens- 18 \\
\hline Palm & 7.89 & 22 & 50 & 4.8 & 2 & hand-54, tree-50, lines- 29, leaves- 23, skin- 19 \\
\hline Vegetable & & & & 5.1 & 0 & green-31, eatable- 27, grows- 27, good- 25, leaves- 19 \\
\hline Carrot & 9.52 & 42 & 47 & 5.9 & 1 & orange -88 , vegetable -47 , rabbit- 31 , long- 29 , hard -26 \\
\hline Celery & 8.52 & 40 & 58 & 5.4 & 2 & green -90 , vegetable -58 , stalk -42 , leaves -42 , strings -23 \\
\hline Corn & 9.41 & 31 & 49 & 6.0 & 2 & yellow- 79 , kernals- 51 , vegetable -49 , cob- 38 , stalk- 38 \\
\hline Parsnip & 5.96 & 32 & 45 & 2.3 & 0 & vegetable- 45 , green- 29 , don't know-18, eatable- 14 , plant- 12 \\
\hline Rice & 3.89 & 24 & 6 & 4.7 & 1 & white -65 , food -39 , small- 29 , eatable- 28 , China- 25 \\
\hline Yam & 6.30 & 34 & 22 & 3.9 & 1 & orange -52 , sweet -28 , potato -26 , vegetable- 22 , sweet potato- 18 \\
\hline Vehicle & & & & 5.1 & 1 & wheels- 69 , moves- 37 , transportation- 33 , car -31 , metal- 16 \\
\hline Car & 9.97 & 44 & 7 & 7.3 & 1 & wheels- 66 , seats -43 , tires- 39 , steers- 32 , transportation- 30 \\
\hline Truck & 9.57 & 49 & 13 & 5.5 & 1 & wheels- 67 , tires- 33 , engine- 28 , big- 24 , metal- 17 \\
\hline Van & 9.30 & 44 & 15 & 4.9 & 0 & wheels-37, truck-25, big-23, vehicle- 15 , colored -12 \\
\hline Airplane & 8.33 & 58 & 9 & 8.6 & 3 & wings- 78 , flies- 57 , engines- 50 , transportation -43 , seats- 36 \\
\hline Raft & 5.57 & 16 & 4 & 4.8 & 2 & floats -68 , wood -57, water- $24, \operatorname{logs}-10$, rubber- 10 \\
\hline Train & 9.17 & 28 & 6 & 5.5 & 0 & caboose -43 , tracks -40 , wheels- 36 , engine- 34 , cars -30 \\
\hline Weapon & & & & 4.5 & 0 & kills-38, dangerous- 34 , gun-25, knife- 23 , metal-21 \\
\hline Gun & 9.61 & 37 & 20 & 5.9 & 4 & trigger- 61 , bullets -56 , shoots- 50 , barrel-50, metal -48 \\
\hline Knife & 9.17 & 32 & 20 & 6.1 & 2 & sharp -94 , cut -57 , handle -45 , blade -41 , metal -35 \\
\hline Sword & 8.10 & 39 & 29 & 5.5 & 1 & sharp -63 , handle- 37 , metal- 35 , long- 29 , point- 29 \\
\hline Poison & 7.17 & 17 & 0 & 4.0 & 0 & dangerous -43 , kills- 33 , liquid- 22 , harmful- 18 , deadly -17 \\
\hline Rock & 5.74 & 7 & 0 & 4.6 & 1 & hard -77 , heavy -21 , mineral- 17 , stone- 15 , small-11 \\
\hline Whip & 6.58 & 21 & 0 & 4.4 & 1 & long-51, leather -47 , handle-22, cracks- 20 , pain- 18 \\
\hline Plant & & & & 5.4 & 2 & green- 80 , leaves- 54 , flower- 41 , grows- 35, stem- 33 \\
\hline Animal & & & & 5.0 & 0 & legs- 36 , fur- 30 , lives- 27 , breathes- 17 , wild- 15 \\
\hline
\end{tabular}

Note-Column 1: rated typicality; Column 2: percent property overlap to the superordinate; Column 3: percent dominance of the superordinate; Column 4: mean number of generated properties; Column 5: number of properties with frequency $>50 \%$. Column 6 : five most frequent properties and their dominance.

"The first item listed for each category' is the category label: the remaining items are category members. 


\section{REFERENCE NOTE}

1. Ashcraft, M. H. Property norms for typical and atypical items from 17 categories. Unpublished manuscript, 1976. (Available from the author, Department of Psychology, Cleveland State University, Cleveland, Ohio 44115.)

\section{REFERENCES}

AshCraft, M. H. Priming and property dominance effects in semantic memory. Memory \& Cognition, 1976, 4, 490-500.

Ashcraft, M. H. Property dominance and typicality effects in property statement verification. Journal of Verbal Leaming and Verbal Behavior, in press.

Battig, W. F., \& Montague, W. E. Category norms for verbal items in 56 categories: A replication and extension of the Connecticut category norms. Joumal of Experimental Psychology Monograph, 1969, 80(No. 3, Part 2).

Collins, A. M., \& Loftus, E. F. A spreading-activation theory of semantic processing. Psychological Review, 1975, 82. $407-428$.

Collins, A. M., \& Quillian, M. R. Retrieval time from semantic memory. Journal of Verbal Learning and Verbal Behavior, 1969, 8, 240-247.

Collins, A. M., \& Quillian, M. R. Facilitating retrieval from semantic memory: The effect of repeating part of an inference. Acta Psychologica, 1970, 33, 304-314.

Colurns, A. M., \& Quilinan, M. R. How to make a language user. In E. Tulving \& W. Donaldson (Eds.), Organization of memory. New York: Academic Press, 1972.

ConRAD, C. Cognitive economy in semantic memory. Journal of Experimental Psychology, 1972, 92, 149-154.

Glass, A. L., Holyoak, K. J., \& O'Dell, C. Production frequency and the verification of quantified statements.
Journal of Verbal Learning and Verbal Behavior, 1974, 13. 237-254.

Holyonx, K. J., Glass, A. L., \& MAH, W. A. Morphological structure and semantic retrieval. Journal of Verbal Leaming and Verbal Behavior, 1976, 15, 235-247.

KINTSCH, W. The representation of meaning in memory. Hillsdale, N.J: Lawrence Erlbaum, 1974.

LofTus, E. F., \& Suppes, P. Structural variables that determine the speed of retrieving words from long-term memory. Journal of Verbal Learning and Verbal Behavior, 1972, 11, 770-777.

Nelson, K. E., \& Kosscyn, S. M. Semantic retrieval in children and adults. Developmental Psychology, 1975, 11. 807-813.

Norman, D. A., \& Rumelhart, D. E. Explorations in cognition. San Francisco: W. H. Freeman, 1975.

RIPS, L. J. Inductive judgments about natural categories. Journal of Verbal Learning and Verbal Behavior, 1975, 14. 665-681.

Rosch, E. Cognitive representations of semantic categories. Journal of Experimental Psychology: General, 1975, 104. 192-233.

Rosch, E., \& Mervis, C. B. Family resemblances: Studies in the internal structure of categories. Cognitive Psychology, $1975,7,573-605$.

SmIrh, E. E., Rips, L. J., \& Shoben, E. J. Semantic memory and psychological semantics. In G. H. Bower (Ed.), The psychology of learning and motivation (Vol. 8). New York: Academic Press, 1974.

(Received for publication July 15. 1977; revision accepted December 12, 1977.) 